\title{
Design and Implementation of Students' projects allocation System
}

\author{
Amadi, Anthony Ndubuisi; Ololo, Emmanuel Chimezie \\ Computer Science Department, Imo State Polytechnic, Umuagwo, Nigeria \\ DOI: 10.29322/IJSRP.11.06.2021.p11424 \\ http://dx.doi.org/10.29322/IJSRP.11.06.2021.p11424
}

\begin{abstract}
This work is on design and implementation of a software system for students' projects (dissertation) allocation system. It will be used to enable final year students of Imo State Polytechnic Umuagwo apply for projects and upload completed project. Model View Controller (MVC) methodology was used in the in designing the system. The database used is MySQL, while implementation was done with PHP. Primary and secondary sources were used for data collection. The result of the research is the development of a project allocation system that successfully allows students to apply for projects online; which the supervisors will mark and the system allocates a project to the student using the highest score awarded to the student's proposals by the supervisor.
\end{abstract}

Index Terms- Dissertation, project allocation, supervisor, allocation system.

\section{INTRODUCTION}

$\mathrm{T}$ his is an online students' projects allocation System. Com 429 and Com 229 are titled "Project" and offered by final year students for the award of Higher National Diploma and National Diploma anticipated cost of completing the project. This work is to discuss the design and implementation of online Project Allocation System, a software system that tends to provide an alternative solution to the manual project allocation system of Imo State Polytechnic, Umuagwo, Imo State, Nigeria. The case Study is Computer Science Department. Using this system, the admin user is expected to invite the students to join the system. A link is sent to them to enable them reset their password. After this is successfully done, they can login to propose for projects. Each student is expected to submit three proposals to their supervisor. The supervisor goes through an application and marks them by assigning numerical scores ranging from 1-5 marks to pre-determined criteria that make up the proposal. The system uses an algorithm to automatically allocate a project to a student if the student has obtained at least half of the total score. Where more than one score is above half of the total score, the system selects the highest score obtained by the student and allocates the project to the student. Where the score on two proposed topics are equal, any one of them is assigned to the student. The entire process is computerized and the user interface is user friendly. The system tries to solve the problem of duplication of topic on yearly basis, delay in reaching a supervisor for project allocation, and that of providing an accessible database for students' projects contents. 


\section{Statement of the Problem}

The problem of using a manual system (pen and paper register) in the management and allocation of projects to students is characterized by a lot of problems which include:

1. Inability of the project supervisors to know whether a particular topic has been approved already for a student.

2. Difficulty and improper documentation of allocated project topics.

3. Inefficiency in entering, updating and retrieving records of allocated projects.

4. Difficulty in accessing project supervisors for approval of topic.

5. Duplication in project topics approved for students.

6. Difficulty in accessing softcopy of past projects.

These problems prompted the development of an online project allocation system to address these challenges.

\section{Aim and Objectives of the Study}

The aim of this study is to develop an online project allocation system which will help the computer science department of Imo State polytechnic to efficiently manage projects allocation to students. The specific objectives are:

1. To design the interfaces required to implement this system.

2. To create a database that will be used to store projects and allocations.

3. To implement the design using PHP as the programming language.

\section{Literature Review}

Resource allocation is an integral aspect of any organization. It is the responsibility of management to ensure the efficient allocation of organization's resources. Decision-making function may not be effective if the required information with which the decision will be made is not available at the right time. Resource allocation is geared towards achieving the organization's purpose. Resources are acquired, allocated, motivated and manipulated by the manager's control. This include: plant and equipment, people, materials, money, and information.

In a Polytechnic environment, conducting research in areas chosen by the students or academic is a prerequisite for meriting a degree or diploma. The Institution oversees that courses are taught and award of degree or diploma given to students who satisfactorily and successfully completed a predetermined course of study that is offered by the institution, and also found worthy in character. Central to all diplomas is a project that students have to undertake and submit in support of their candidature for their National Diploma (ND) or Higher National Diploma (HND). Part of this process is the selection and allocation of final year projects involving This publication is licensed under Creative Commons Attribution CC BY. 
both academic staff and students. "Whilst the Students Project Allocation (SPA) problem from a resource allocation perspective is not an especially complex one, aspects of the aforementioned methodology are still relevant and can be utilized in a basic form to aid in this project's success. At a conceptual level, the SPA problem relating to the Department of Computer Science involves three core objects/entities: students, projects and supervisors" Morgan (2012).

The students need a project topic and an academic for supervisor, who has adequate ability to supervise the project and a willingness to do so; to complete a student's project.

From the student's point of view, once the pairing is satisfied, "then one can say that the appropriate resources have been successfully allocated to allow both the University and students to meet their primary purposes: that students have a suitable project to undertake, and that the University enables the student to go on and complete their chosen program of enrolment whist making sure that its academic staff have a balanced workload" Morgan (2012).

In some institutions abroad, the institution has a list of projects they want to embark on for a particular session. The call for projects takes the form of an email to supervisors requesting that they write their project proposals and upload them to an online learning environment used by the institution. A project proposal basically has a project title, a detailed description and the maximum number of students that will work on the project. At completion, it is uploaded to the institutions website. It is the duty of support staff to browse through the list of projects to check whether any supervisor has not uploaded sufficient number of projects. If this is the case, an email is sent to them reminding them to upload more project proposals. Bouakaz (2015)

Next is the release of the project proposals to students. A few weeks prior to the project allocation week, students are given access to the site where they can view all of the supervisors' projects for the session. An email is sent out to the students to notify them that the list of proposals has become available to view. Discussion board is available for questions and answers about the various topics. During the project allocation week, a student formally requests a project from the supervisor through the online platform. Usually, a student request for a project; the supervisor chooses the student to make the offer to; An offer notification is sent by the supervisor to the student by email; students accept an offer and the project is considered to be allocated Bouakaz (2015).

The Student Project Allocation problem (SPA) is a many-to-one matching problem and is an extension of the extensively studied one-to-one Stable Marriage Problem (SMP). Although a complete and comprehensive solution to the many-to-one matching problem has yet to be found, there are many comparable examples that offer a solution based on allowing a level of compromise within the results they obtain.

The Department of Computer Science, University of York is one of the Universities in UK that has a working Student Projects allocation system: A. J. Fisher computerised the project allocation process in 1998 with the This publication is licensed under Creative Commons Attribution CC BY. 
aim to reduce the amount of administration time needed by students, academics, and administrative staff in allocating projects to students. He also had the intention to make the process fairer. The system manipulates input data to make it fit the GS algorithm by preventing the scenario from occurring in which students could end up without a project. Although it is not perfect, it has proven to be fairly successful. In 2000, Jonathan Dyer, a then student of the department, worked on the same project to improve the algorithm used by A. J. Fisher designed by taking a constraint logic programming approach. The system he constructed was not entirely successful because it took too long to find useful results However; Jonathan's work was able to provide new possible areas of research which could help produce a useful system (Morgan, 2012).

\section{Conflict Resolution}

According to Dechter (1991), Conflict resolution governs constraint satisfaction and resource allocation. It provides a framework for constraints to be defined and how resources should be allocated. Conflict situations can are in two categories: The first is competitive conflict situations, in which each party only has their own interests at heart and neither party desires to reach a globally optimal situation unless it proves beneficial to them; the second, cooperative conflict situations, involves both parties being united in achieving a higher goal to reach a globally optimal solution. Klein said "This often requires the sacrifice of personal benefits in the interest of achieving the higher goal." "Psychological, the relationship between two (or more) parties - the level of trust and friendship may affect conflict resolution. Bias may be introduced in the process. Automating the allocation process would make it fair to all parties involved.

\section{Project allocation Process}

In some institutions abroad, the institution has a list of projects they want to embark on for a particular session. The call for projects takes the form of an email to supervisors requesting that they write their project proposals and upload them to an online learning environment used by the institution. A project proposal basically has a project title, a detailed description and the maximum number of students that will work on the project. At completion, it is uploaded to the institutions website. It is the duty of a support staff to browse through the list of projects to check whether any supervisor has not uploaded sufficient number of projects. If this is the case, an email is sent to them reminding them to upload more project proposals. Bouakaz (2015)

Next is the release of the project proposals to students. A few weeks prior to the project allocation week, students are given access to the site where they can view all of the supervisors' projects for the session. An email is sent out to the students to notify them that the list of proposals has become available to view. Discussion board is available for questions and answers about the various topics. During the project allocation week, a student formally requests a project from the supervisor through the online platform. More than one student may request for a project but the supervisor may choose a student that will work on the project. An offer 
is then sent by the supervisor to the student by email, at which point the student will have 24 hours to accept the offer. Given that students can (and are expected to) request more than one project, they may receive several offers during the week but may only accept one offer. If an offer is accepted, the student is committing to take that project and is invariably declining any other offers they have received. Once an offer has been accepted by a student, that project is considered to be allocated Bouakaz (2015).

\section{Methodology}

The researcher made use of the internationally accepted software engineering model - Model View Controller (MVC) in the development of this system. This research methodology includes the specification of procedure for collection and analysis of data necessary to define or solve the problem for which the research is embarked upon. Data collected for this research work made it possible for the researcher to have an insight of how the current system works and also assisted to design the new system. Sources of data include:
a. Interview with students and staff.
b. Observation
c. Examination of document 


\section{System Design}

\section{ER-Diagrams}

Figure 1: ER-Diagrams

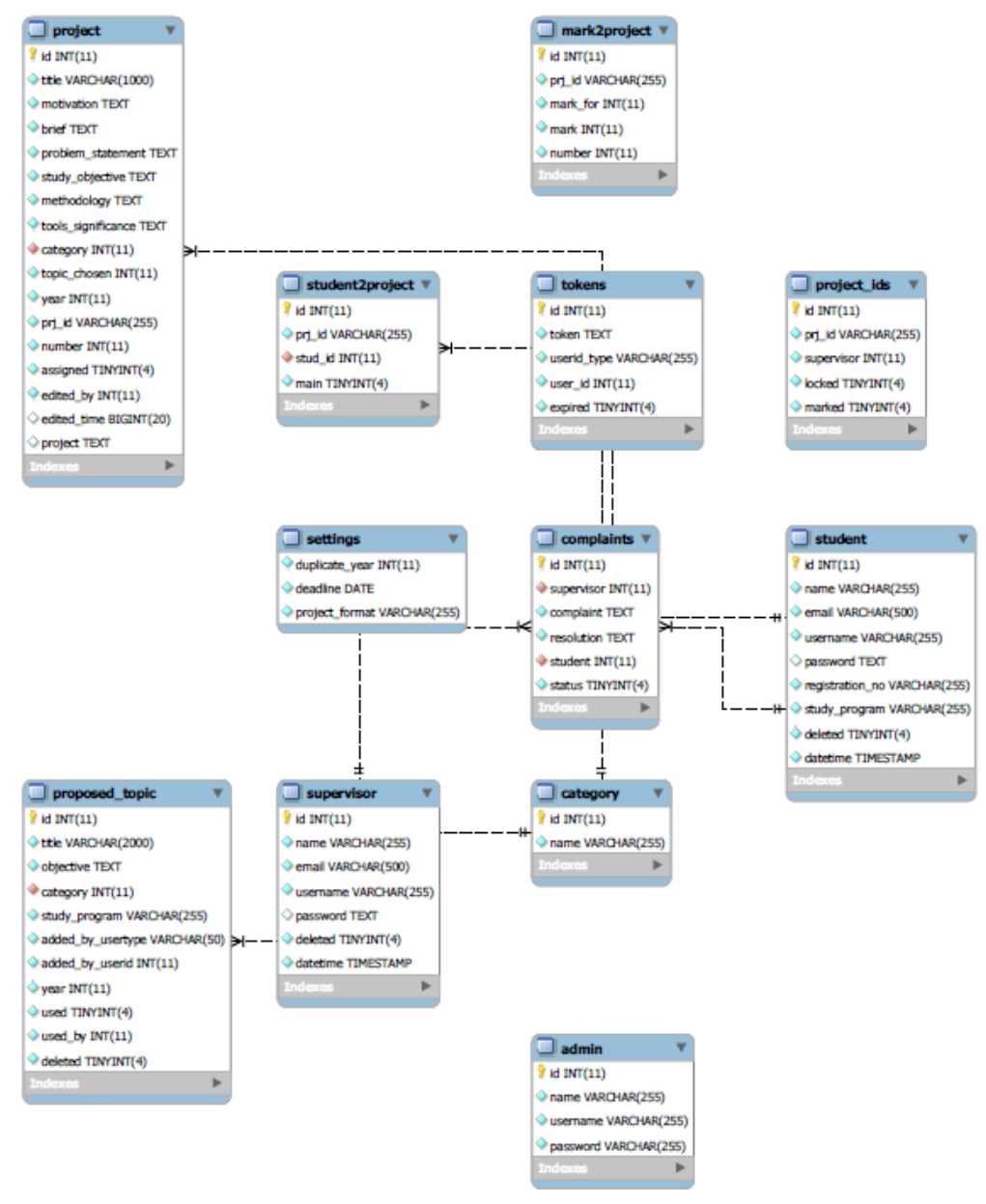

\section{High level Use case Diagrams}

Figure 4.8 is the Use Case Diagram which shows the three actors (Admin, Student and Supervisor) who will use the system. It also shows that the project allocation is automated. 


\section{Figure 2: Use Case Diagrams}

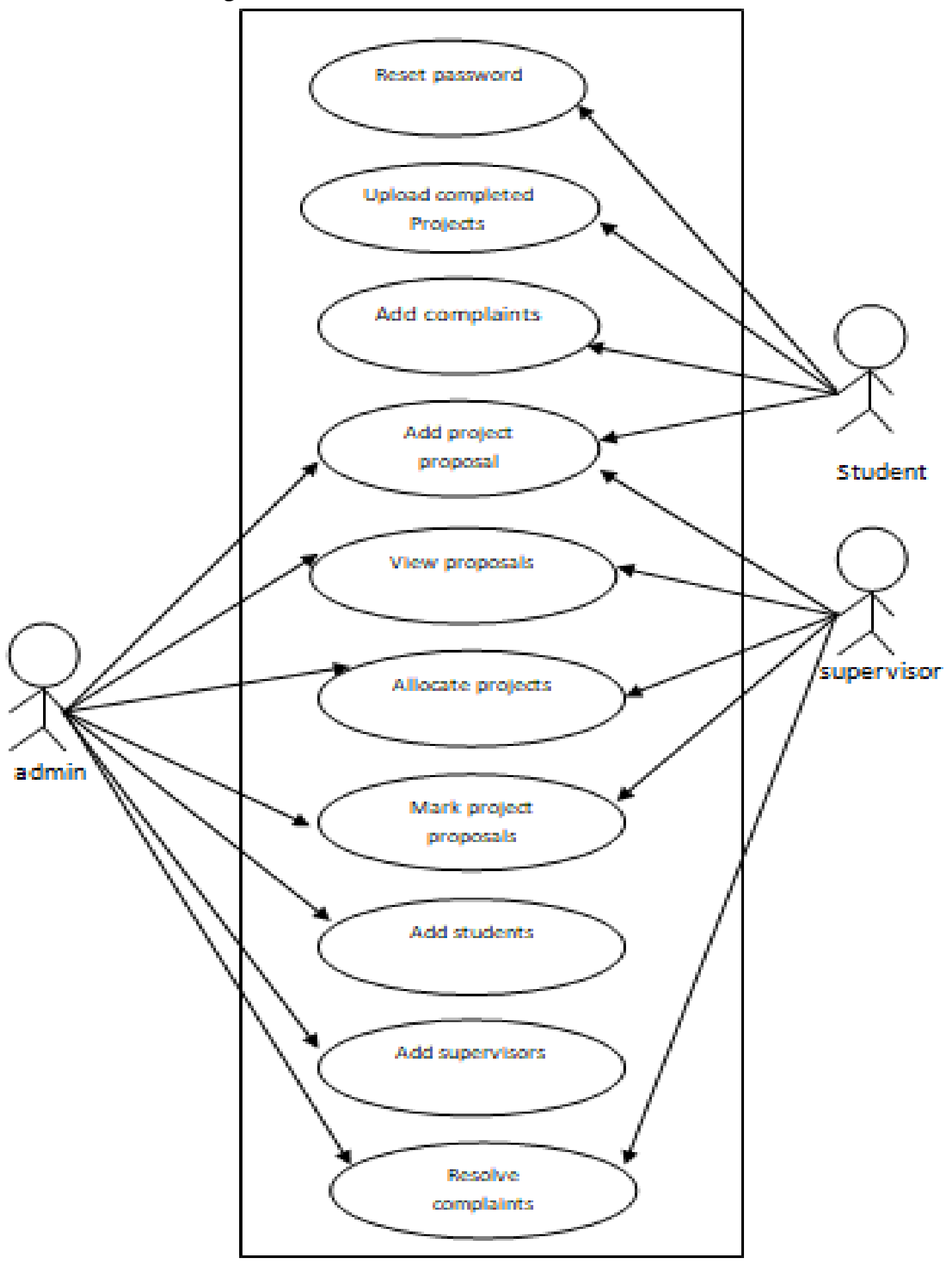




\section{Figure 3: Use case for Managing the system}

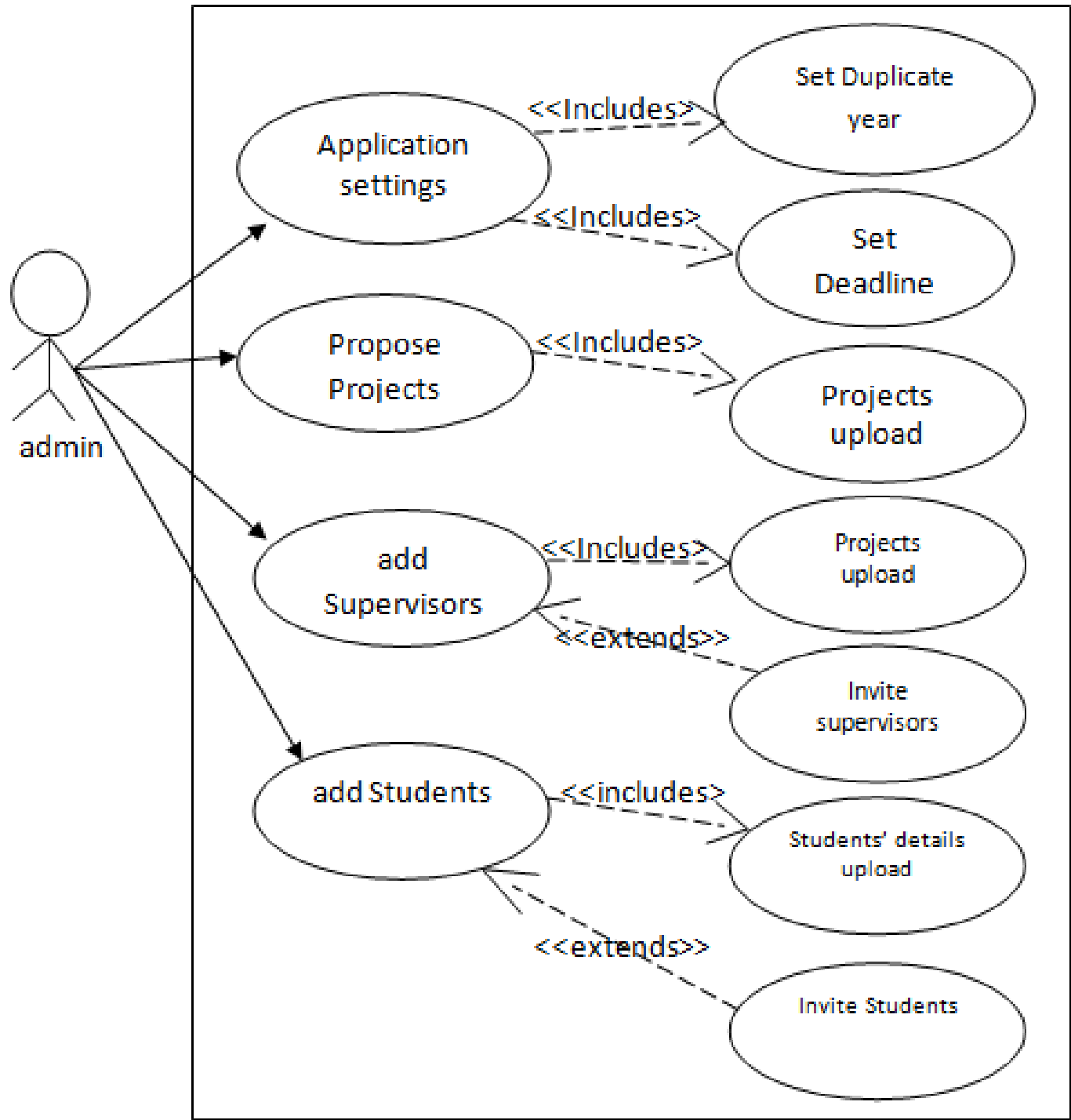




\section{Interface Designs}

\section{Figure 4: Admin Dashboard}



The admin dash board enables him to manage the system which includes: To add students and supervisors, view students and supervisors, propose projects view submitted projects; setting of deadline, changing of password and setting of duplicate year of topics allowed by the system.

\section{Figure 5: Supervisors' Dashboard}



The supervisor dashboard enables him to manage students' project proposals which include: View students' proposals, propose projects, view submitted projects; respond to students complaints and changing of his password. 


\section{Figure 6: Student's Dashboard}

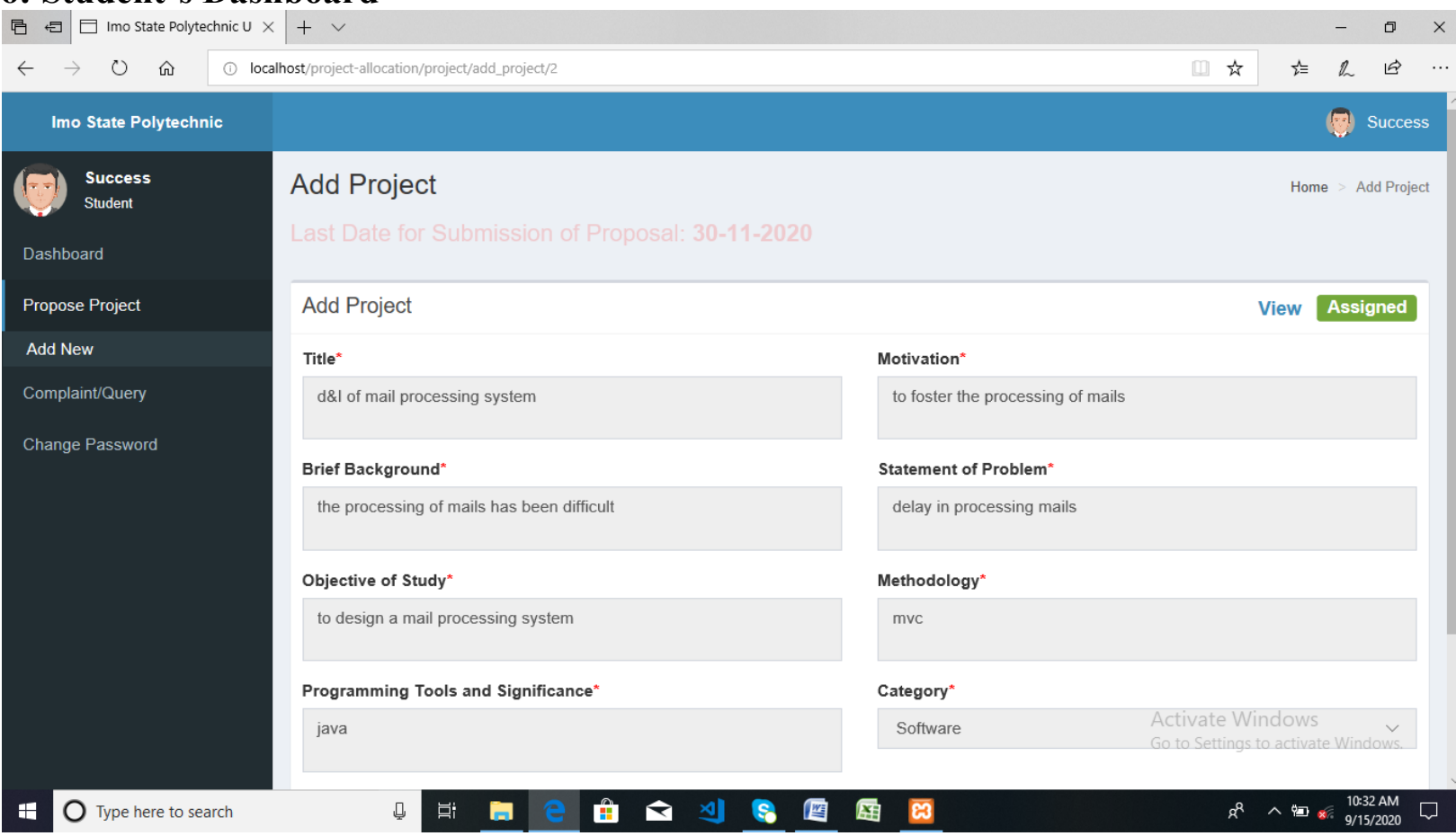

The student's dashboard enables him to: Apply for projects, view feedback of application, submit complaints about project, upload completed project document, and reset password.

\section{CONCLUSION}

This software development research work was a success to the extent that the software developed can be deployed online for better management of students' project allocation after they have been allocated to supervisors. The students can propose their topics and have their respective supervisors' access and evaluate the proposals while the system allocates the topic with the highest point to the student. At the end of the project, the student uploads the .pdf file of completed work. A supervisor also has the privileges to suggest research topics from the supervisor page which may be used by the students in making their proposals. If this software product is deployed, it will bridge the communication gap between students and their supervisors which will ensure better service delivery.

\section{REFERENCES}

[1] Morgan. W. (2012). A Project Allocation System, Dissertation submitted to the University of Sheffield, UK.

[2] Bouakaz, L. (2015) An Online Portal for the Selection and Allocation of Dissertation Projects, The University of Sheffield. UK. 
[3] Dechter, R. (1991). “Constraint Satisfaction” Department of Computer Science and Information Science, University of California, Irvine, http://citeseer.ist.psu.edu/viewdoc/summary?doi=10.1.1.35.6973.

\section{AUTHORS}

First Author - Amadi Anthony, MSc Software Systems, Imo State Polytechnic Umuagwo, Nigeria; email: toonex32@gmail.com Second Author - Ololo, Emmanuel Chimezie, Imo State Polytechnic Umuagwo, Nigeria; email: meetexcess_386@yahoo.com 